\title{
LIBERDADE E NECESSIDADE EM FRIEDRICH ENGELS. A CONTRIBUIÇÃO DOS ESCRITOS DE MIKHAIL LIFSCHITS DA DÉCADA DE 1960
}

\author{
LIBERTAD Y NECESIDAD EN FRIEDRICH ENGELS. LA CONTRIBUCIÓN DE LOS \\ ESCRITOS DE MIJAÍL LIFSCHITZ DE LA DÉCADA DE 1960
}

\section{FREEDOM AND NECESSITY IN FRIEDRICH ENGELS. THE CONTRIBUTION OF MIKHAIL LIFSHITZ'S WRITINGS FROM THE 1960S}

\begin{abstract}
Víctor Antonio Carrión ${ }^{1}$
Resumo: Neste artigo, se faz una revisão de como, nos anos 60 do século XX, o chamado marxismo ocidental desautorizou os escritos filosóficos de Friedrich Engels, pelo fato de considera-los alheios ao autêntico pensamento do Marx no que diz respeito a dialética da natureza, teoria do reflexo e a relação entre necessidade e liberdade, isto último expressado com particular agudeza na discussão da estética marxista. Retomando os escritos do filósofo soviéticos Mikhail Lifschits, nós evidenciamos as consequências práticas das posturas estéticas dos marxistas ocidentais, contrárias a todo movimento democrático com base nas massas trabalhadoras
\end{abstract}

Palavras-chave: Engels, Lifschits, marxismo, dialética, liberdade, arte, Sartre.

Resumen: El presente artículo repasa como, en los años 60 del siglo XX, el autodenominado marxismo occidental desautorizó los escritos filosóficos de Friedrich Engels, por considerarlos ajenos al auténtico pensamiento de Marx en lo relativo a la dialéctica de la naturaleza, la teoría del reflejo y la relación entre necesidad y libertad, esto último expresado con particular agudeza en la discusión sobre la estética marxista. Retomando los escritos del filósofo y crítico de arte soviético Mijaíl Lifschitz se evidencia que las consecuencias prácticas de las posturas estéticas de los marxistas occidentales son contrarias a todo movimiento democrático con base en las masas trabajadoras.

Palabras clave: Engels, Lifschitz, marxismo, dialéctica, libertad, arte, Sartre.

Abstract: This paper reviews how, in the 60s of the 20th century, self-called Western Marxism disavowed the philosophical writings of Friedrich Engels, considering them alien to Marx's authentic thought regarding the dialectic of nature, the theory of reflection, and the relationship between necessity and freedom. The latter relationship expresses itself with particular acuity in the discussion on Marxist aesthetics. Taking up the writings of the Soviet philosopher and art critic Mikhail Lifshitz, it is evident that the practical consequences of Western Marxists' aesthetic positions are opposed to any democratic movement based on the working masses.

Keywords: Engels, Lifshitz, marxisms, dialectics, freedom, art, Sartre.

\section{La creación contra la dialéctica}

En los años 60 del siglo XX se posicionó en el mundo académico una versión del marxismo que luego se denominó como marxismo occidental y cuya influencia se incrementó en el período posterior a la derrota del proletariado soviético en 1991. Común a las diversas escuelas de marxismo occidental es la consideración de Engels como una "serpiente diabólica que incita a ese pecado original de donde supuestamente - se deriva todo lo vulgar, lo dogmático, lo mecanicista y antidialéctico del marxismo ortodoxo”(PIEDRA ARENCIBIA, 2019, p. 66)2. 
En la obra de Jean-Paul Sartre, "Crítica de la razón dialéctica", se sintetizan los argumentos repetidos una y otra vez por los marxistas antiengelsianos. Para el existencialista francés, toda posición materialista es ineludiblemente positivista y, por lo tanto, incompatible con la dialéctica, pues si "el pensamiento no es el todo, asistirá a su propio desarrollo como una sucesión empírica de momentos, y esta experiencia le entregará lo vivido como contingencia y no como necesidad" y si "el Conocimiento tiene que dejar que el Ser se desarrolle según sus propias leyes, ¿cómo evitar que los procesos... no se den como empíricos?" (SARTRE, 1963, p. 171). Siendo así, y puesto que "las leyes científicas son hipótesis experimentales verificadas por los hechos", la afirmación de la universalidad de la dialéctica en la naturaleza no es susceptible de ninguna verificación, “[s]i se declara que un conjunto de leyes establecidas por los sabios representa a cierto movimiento dialéctico en los objetos de esas leyes, no se tiene ningún medio válido de probarlo" (SARTRE, 1963, p. 175).

De tal manera, hablar de dialéctica de la naturaleza es imponer una regla a priori, un principio místico que suprime "al hombre desintegrándolo en el universo”, la dialéctica como ley del mundo, como verdad del ser es "idealismo dogmático" que "lleva necesariamente a la teoría del reflejo, a dar al hombre una razón constituida, es decir, a hacer del pensamiento un comportamiento rigurosamente condicionado por el mundo (lo que es), omitiendo decirnos que es también conocimiento del mundo" (SARTRE, 1963, p. 177).

En la concepción sartreana Engels despoja a la dialéctica de su racionalidad y la convierte en una fatalidad metafísica que disuelve a los individuos reales “en un baño de ácido sulfúrico” subordinándolos a "no sé qué conjuntos superindividuales", ya que "la dialéctica, si existe, es la aventura singular de su objeto. No puede haber en ninguna parte, ni en una cabeza ni en el cielo inteligible, un esquema preestablecido que se imponga a los desarrollos singulares” (SARTRE, 1963, p. 185)³.

Según el argumento antiengelsiano de existir la dialéctica la naturaleza el proceso de desarrollo social se regiría por leyes naturales que actúan a espaldas de los individuos sin importar lo que estos hagan. En opinión de Gajo Petrović, en tanto la praxis es "la actividad creadora, libre" esta es incompatible con la postura "la libertad como la necesidad conocida" pues esta última esclaviza al individuo a un desarrollo predeterminado (PETROVIC, 1985, pp. 47, 51), pero si el ser humano es creador, si las masas pueden cambiar la historia con su acción revolucionaria toda dialéctica de la naturaleza es imposible pues la dialéctica solo existe y surge en y por la praxis humana.

En la década de 1960, la voz de Sartre se unió a la de Ernst Fischer y Roger Garaudy, "es necesario rechazar a priori el concepto de decadencia" dijo en relación al llamado arte de vanguardias "occidental", ya que en abstraccionistas, cubistas y escritores modernistas no es posible constatar decadencia alguna ya que, al contrario, todo esto forma parte integral de la cultura de izquierda occidental (SARTRE et al., 1964). Garaudy no solo repudió el concepto de decadencia, sino que disolvió toda diferencia entre ascenso y putrefacción al concebir que el objeto del arte "no es satisfacer una necesidad particular del hombre, sino su necesidad específicamente humana de objetivarse como creador" 
(GARAUDY, 1963, p. 256).Y la creación solo será digna de tal nombre al liberarse de toda atadura e imposición del mundo objetivo, al alcanzar un punto en que "el criterio de belleza ya no exige referencia a una realidad exterior a la obra" y lo real pasa a ser "función de la actividad del hombre" (GARAUDY, 1963, pp. 260-261). Lo sensible es desplazado por la creación de equivalencias plásticas capaces de expresar la vivencia de "fuerzas invisibles", el arte ya no es reflejo, imitación, sino creación:

El lenguaje del arte está estrechamente ligado a su objeto. Este es necesariamente, como tal, inexpresable. Es creador de mitos, es decir, de un "modelo" del hombre por hacerse, y más allá del concepto que expresa lo que ya está hecho, es poesía o símbolo, es decir, reencuentro inesperado de término que no nos da una realidad ya hecha, sino que nos indica, nos hace ver una realidad por hacerse... / El mito testimonia la presencia activa, creadora, del hombre en un mundo siempre en nacimiento y crecimiento. Toda gran obra de arte es uno de esos mitos. / El arte es por tanto conocimiento, pero conocimiento específico por su objeto y por su lenguaje: conocimiento por el hombre de su poder creador y en el lenguaje inexpresable de la poesía (GARAUDY, 1963, p. 267).

En Garaudy la humanidad una vez libre de la dialéctica de la naturaleza y de la teoría del reflejo encuentra la auténtica libertad:

En la concepción judeo-cristiana... la creación es lo primero, y la libertad del hombre, no se define ya como conciencia de la necesidad, sino como participación en el acto creador (GARAUDY, 1970).

El acto creador supremo es la "Resurrección de Cristo", "el paradigma de esta nueva libertad" que supera al anquilosado materialismo dogmático.

\section{Libertad y dialéctica de la naturaleza}

Sartre ve en el pensamiento de Engels el intento dogmático de aplicar principios a priori en la naturaleza y proyectarlos a la sociedad negando así la libertad del individuo. En la base de esta postura está la noción de una naturaleza que no puede ser dialéctica porque todo conocimiento científico natural es ineludiblemente empírico, contingente y a lo sumo hipotético. El único mundo organizado es aquel ya transformado por la praxis humana en tanto la "naturaleza sin el hombre" es un mundo no organizado y no inteligible (SARTRE, 1963, pp. 173, 180-181).

Si bien "[t]odas las formas discursivas que parten de lo singular son experimentales, descansan sobre la experiencia", esto no significa que la ciencia natural sea el dominio indiscutido de la inducción y el empirismo (ENGELS, 1961, p. 192). Quienes ven en la inducción la única vía de conocimiento de la naturaleza, suponen que siempre se pasa del juicio singular que registra el hecho aislado al juicio de lo particular que agrupa los hechos sueltos en una clase y verifica la transición de una en otra para llegar al juicio de lo universal, su expresión en forma de ley natural. Considerar el conocimiento de la naturaleza únicamente como un conjunto de momentos empíricos y contingentes degrada todo juicio universal al nivel de una hipótesis o, peor aún, al de una de tantas creencias y visiones que junto a otras tienen igual derecho a explicar el universo (religión, superstición, etc.) (ENGELS, 1961, p. 191).

El fragmento "Los naturalistas en el mundo de los espíritus" de Engels resume de manera genial 
el inexorable paso del empirismo (y también del omniinduccionismo) al espiritismo.

Los extremos se tocan, reza un viejo dicho de la sabiduría popular, impregnado de dialéctica. Difícilmente nos equivocaremos, pues, si buscamos el grado más alto de la quimera, la credulidad y la superstición, no precisamente en la tendencia de las ciencias naturales que, como la filosofía alemana de la naturaleza, trata de encuadrar a la fuerza el mundo objetivo en los marcos de su pensamiento subjetivo, sino, por el contrario, en la tendencia opuesta, que, haciendo hincapié en la simple experiencia, trata al pensamiento con soberano desprecio y llega realmente más allá que ninguna otra en la ausencia de pensamiento (ENGELS, 1961, p. 30).

Afamados científicos, que realizan grandes aportes en la zoología, botánica, química y otros campos, aplican el método de la observación empírica para constatar la realidad del mesmerismo, frenología, espiritismo y presentan pruebas irrefutables del mundo fantasmal, de igual forma a como en tiempo reciente aparecieron quienes decían tener pruebas científicas irrefutables de que la pandemia de 2020 es causada por la redes 5G o que el dióxido de cloro es la cura a todos los males. Y si se objeta a estos creyentes que tales cosas no pueden ser comprobadas, "los visionarios nos replican que estamos equivocados y que no tienen inconveniente en ayudarnos a comprobar también, experimentalmente, los fenómenos espiritistas" (ENGELS, 1961, p. 39).

En realidad, nadie puede despreciar impunemente a la dialéctica. Por mucho desdén que se sienta por todo lo que sea pensamiento teórico, no es posible, sin recurrir a él, relacionar entre sí dos hechos naturales o penetrar en la relación que entre ellos existe. Lo único que cabe preguntarse es si se piensa acertadamente o no, y no cabe duda de que el desdén por la teoría constituye el camino más seguro para pensar de un modo naturalista y, por tanto, falso. Y el pensamiento falso, cuando se le lleva a sus últimas consecuencias, conduce generalmente, según una ley dialéctica ya de antiguo conocida, a lo contrario de su punto de partida. Por donde el desprecio empírico por la dialéctica acarrea el castigo de arrastrar a algunos de los más fríos empíricos a la más necia de todas las supersticiones, al moderno espiritismo (ENGELS, 1961, p. 39).

El candor empirista es impotente ante este tipo de supersticiones, "porque a los espiritistas les tiene sin cuidado el que cientos de supuestos hechos resulten ser un fraude y docenas de supuestos médiums sean desenmascarados como vulgares estafadores. Mientras no se hayan descartado, uno por uno, todos los supuestos portentos, siempre les quedará terreno bastante donde pisar..." (ENGELS, 1961, pp. 39-40) y porque la superstición frecuentemente se apoya en el empirismo estrecho pues le permite argumentar que la prueba positiva de los fenómenos sobrenaturales aún está por encontrarse y por ello no se puede descartar su existencia.

El empirismo ya abraza al misticismo al convertir en un absoluto la afirmación "solo podemos conocer lo finito" pues "nos hallamos más o menos circunscritos a nuestra pequeña tierra". Dogma empirista asumido por Sartre al afirmar que la dialéctica de la naturaleza es indemostrable ya que esta solo tiene sustento racional en nuestra praxis, que solo es una parcela en medio del amplío universo. Argumento bastante antiguo y al que Engels ya se enfrentó en sus manuscritos. Para el gran amigo de Marx solo podemos conocer lo finito, pero en el fondo, sólo podemos conocer lo infinito, "todo conocimiento verdadero y exhaustivo consiste simplemente en elevarse, en el pensamiento, de lo singular a lo especial y de lo especial a lo universal, en descubrir y fijar lo infinito en lo finito, lo eterno en lo perecedero" (ENGELS, 1961, pp. 198-199). El conocimiento de la infinitud se da en y a través de la finitud, toda 
conclusión inductiva es la fijación de lo universal en lo individual (y en tal sentido se convierte en su contrario, deducción), una negación que es a su vez negada.

Así como la infinitud de la materia cognoscible se halla integrada por una serie de finitudes, la infinitud del pensamiento que conoce de un modo absoluto se halla formada también por un número infinito de mentes humanas finitas, que laboran conjunta o sucesivamente por alcanzar este conocimiento infinito, cometiendo pifias prácticas y teóricas, partiendo de premisas erróneas, unilaterales, falsas, siguiendo derroteros equivocados, torcidos e inseguros y, no pocas veces, sin acertar siquiera a llegar a resultados certeros cuando se dan de bruces con ellos... (ENGELS, 1961, p. 199)

En la concepción de Engels, nuestro pensamiento "es tan soberano cuanto no soberano, y su capacidad de conocimiento es tan ilimitada como limitada", ilimitada según la "disposición, la inspiración, la posibilidad, el objetivo histórico final” y limitada "según la realización individual y la realidad de cada momento" (ENGELS, 1968, p. 76). Todo lo finito que cae en nuestro radio de acción es lo infinito en el interior de ese proceso en el que nos acercamos al conocimiento de la infinitud por medio de la finitud.

Para Sartre la dialéctica de la naturaleza es irracional e innecesaria en tanto la dialéctica en general fue descubierta y definida "en las relaciones del hombre con la materia y en las de los hombres entre sí" (SARTRE, 1963, p. 174), esta nada tiene que hacer en la naturaleza "extrahumana” o en las ciencias naturales. Evidenciándose esa división absoluta entre humanidad y naturaleza que es consustancial a toda concepción que limita la dialéctica al mundo social, pues para ello siempre debe recurrir a la más tosca concepción empirista del conocimiento en general y de las ciencias naturales en particular ${ }^{4}$. El prejuicio empirista de los enemigos de la dialéctica de la naturaleza confluye con la visión metafísica de la casualidad y la necesidad: si nuestro conocimiento es finito y contingente entonces "lo que puede reducirse a leyes, o sea lo que se conoce, es interesante y lo que no se conoce, lo que no se sabe reducir a leyes, indiferente y que, por tanto, se puede prescindir de ello" (ENGELS, 1961, p. 184). Lo que se puede explicar es natural y lo que no se puede explicar se atribuye a lo sobrenatural, tal la consecuencia de la contraposición absoluta entre casualidad y necesidad con la que "cesa toda ciencia, ya que ésta debe precisamente investigar lo que no conocemos" (ENGELS, 1961, p. 184).

Si la dialéctica termina en el mundo de la praxis el más allá es ese mundo no organizado, ininteligible en el que pueden habitar Dios, los espíritus de los muertos o los chakras del tercer ojo. En tanto la praxis guarda para sí el poder de insuflar de dialéctica a un mundo sin dialéctica.

La idea anterior de la necesidad falla. Aferrarse a ella equivale a querer imponer a la naturaleza como una ley la determinación arbitraria del hombre, contradictoria consigo misma y con la realidad, equivale, por tanto, a negar toda necesidad interior en la naturaleza viva y a proclamar de un modo general el caótico reino del acaso como única ley de la naturaleza viviente (ENGELS, 1961, p. 187).

Al abordar el problema de la necesidad y la casualidad, Engels tiene en gran estima la posición de Hegel, en la "Ciencia de la Lógica". Lo casual no tiene fundamento, porque es casual y tiene fundamento porque es casual. Lo casual es lo real que es determinado como posibilidad e imposibilidad, existe como expresión de la unidad inmediata de realidad con posibilidad. Lo necesario es un real que en lo inmediato carece de fundamento, pero tiene realidad por medio de su fundamento. "Lo necesario existe, y este ser 
existente es, él mismo, lo necesario" (HEGEL, 1976, p. 483), la necesidad es el resultado de una larga serie de casualidades y las casualidades resultan del choque de diversas necesidades que se anulan entre sí (ENGELS, 1961, pp. 186-187).

¿Acaso esta concepción de necesidad es compatible con la libertad y con la creación como cualidades humanas?

\section{Libertad y teoría del reflejo}

En los años 60 del siglo XX la discusión sobre la relación de libertad y necesidad se expresó de modo agudo en el ámbito de la estética marxista. Muy conocidas en América Latina fueron las posturas de Ernst Fischer y Roger Garaudy, adscritos a las posiciones del autodenominado marxismo occidental o "antidogmático".

En Fischer el corazón del arte es el mito. Con el final de la Edad Media y la pérdida del mito religioso se formó un vacío tan grande que todo el desarrollo histórico ulterior no ha sido más que una lucha por restablecer o crear una nueva mitología. Una continúa rebelión contra los cánones de la belleza del Renacimiento, primero apelando a la fealdad salvaje y agresiva, luego explorando el mundo lumpen en pos de lo prohibido, condenado y desterrado. Al desplazar la pintura histórica a la religiosa el contenido menguó en favor de la forma, "toda pintura que pretenda representar un acaecimiento histórico se revela como ficción, no como reproducción". La libertad guiando al pueblo de Delacroix "realiza el intento, precursor del futuro, de transformar lo histórico en mítico", ninguna pintura puede reflejar un hecho histórico; el tema, el contenido de tales obras es secundario, lo importante no es el hecho histórico, sino la vivencia que se transmite en la figura, ritmo y color. Lo formal no refleja el mundo externo, sino el ser en $s i ́$ la dimensión subjetiva, psíquica que es la finalidad y cumbre del arte, "la inmersión en la interioridad, en lo difícil e indecible", de modo que el arte es la exteriorización de la introspección, "la desvalorización del tema [religioso o histórico] fue al mismo tiempo un apartarse de la 'ideología', de la consciencia falsa" para ir no hacia lo que es o fue, sino hacia lo que podría ser y así complementar a la razón y la ciencia con la imagen mítica (FISCHER, 1968, passim.).

Para Garaudy, la emancipación del arte da inicio con los impresionistas cuyo mérito histórico fue demostrar "que no existe una visión del mundo exterior válida de una vez por todas" y desafiar el principio de que "el objeto esencial de la pintura era la reproducción de las apariencias sensibles". Merced a la invención de la fotografía la pintura se libera de su función utilitaria de reproducir el mundo lo que permite el advenimiento del cubismo, con el que tenemos finalmente la verdadera pintura. "El objeto ya no es un modelo. La imitación ya no puede ser un fin. El tema ya no puede ser una coartada" (GARAUDY, 1963, pp. 40-41). Con los cubistas se constituye "la creación plástica propiamente dicha", que al ya no estar sometida a la obligación de imitar el mundo natural o social colocará en primer plano sus verdaderas virtudes (GARAUDY, 1963, p. 42). Las leyes de la plástica desplazan a las leyes de la naturaleza, se reivindica "la primacía de la creación sobre la imitación, de proclamar la voluntad de hacer una pintura que 
solo sea pintura", de manera que "[]]a tarea que se asigna la pintura, a partir del cubismo, ya no es la de reproducir el mundo existente, el de la naturaleza, sino de crear un mundo nuevo, un universo propiamente humano" (GARAUDY, 1963, p. 44).

Las posiciones de Fischer y Garaudy aparecieron bajo la pretensión de ser la restitución de la libertad a su justo sitial en la teoría marxista, restauración del auténtico pensamiento de Marx desfigurado por el dogmatismo, en el que el rasgo más importante de la libertad se fija en el poderío del artista para la creación de mitos. En Fischer la personalidad del artista es más libre mientras más se sumerja en sí misma, en su propia dimensión existencial, la verdadera creación no está en reflejar la realidad sino en mixtificarla o, lo que es mejor aún, en prescindir de todo contenido o tema, pues un arte sin contenido es expresión de una individualidad libre de ideologías. Garaudy, por su parte, se levanta contra la tiranía del mundo carnal sensible, el mundo pecaminoso que mancha con su terrenalidad la creación artística, esta debe sacudirse de tan oprobioso yugo para así dar a paso a la creación genuina, la creación de mitos en los que el ser humano por fin contemplará su propio poder.

Es necesario anotar que en la época las traducciones favorecieron la difusión de los puntos de vista de Ernst Ficher, Roger Garaudy, Jiri Hajek y Jean-Paul Sartre, con un único antagonista admitido, Gyorgy Lukács. Por lo que a cincuenta años de distancia, nuestro conocimiento de la discusión en torno a la estética marxista de los años 60 es muy incompleto. La norma era y es que los pensadores provenientes del campo socialista fuesen descartados como dogmáticos, a menos que formasen parte de los “disidentes". Tal vez esta sea la razón por la que se ignoró la voz de Mijaíl Lifschitz, uno de los pensadores marxistas más importantes del siglo XX y partícipe en todos los debates en el campo de la estética y la filosofía que tuvieron lugar a partir de la década de 1920.

Lifschitz ingresó en la polémica de los 60 con su manifiesto, publicado en la revista checoslovaca Estetika, “PPor qué no soy un modernista?” (1964), al que siguieron toda una serie de escritos de tono combativo en los que se disecciona la esencia del modernismo artístico y las posiciones de los marxistas á la Fischer o Garaudy. Sobre estos últimos, no obstante, ya emitió su valoración en comunicaciones privadas recientemente publicadas. En una carta fechada el 26 de noviembre de 1963 dirigida al crítico checoslovaco Vladimir Dóstal, calificó al libro "De un realismo sin fronteras" de Roger Garaudy, de la siguiente forma:

... es el habitual liquidacionismo. Garaudy lo puede todo; él puede, dado el caso, demostrar que el marxismo jamás contradijo el dogma de la inmaculada concepción y por eso los comunistas deben ir cogidos de la mano con los católicos... (LIFSCHITZ, 2018a, pp. 188-189).

Una misiva posterior amplió su valoración de las posiciones de Ernst Fischer, Sartre y Garaudy:

¿acaso cuando se trata acerca de las vías de renacimiento del arte es posible apoyarse en que "no hay mal que por bien no venga" y que al recuperarse de una enfermedad la gente a veces pierde algo? Poco se sabe de lo que ocurre en la realidad concreta, que siempre es más astuta que nuestros esquemas. ¿Acaso por ello es necesario renunciar a las líneas principales? Ya que todas estas digresiones de Fischer y Co. son desde el punto de vista de Lenin: lamentable eclecticismo, lavado de límites, intentos de apoyarse en momentos parciales, en detalles, oscureciendo el sentido del cuadro general, borrando la escala real de las cosas (LIFSCHITZ, 2018a, p. 192). 
En octubre de 1965, Mijaíl Lifschitz le escribió a Lukács; "Ernst Fischer ya llegó del todo a la construcción de dios al modo de 1908-1910. Garaudy hace lo mismo” (LIFSCHITZ; LUKÁCS, 2018, p. 216). La analogía con la desviación surgida entre militantes del partido bolchevique decepcionados por la derrota de 1907 que pretendieron encontrar una salida en la elaboración de una fe religiosa revolucionaria, no era gratuita. Es bien sabido que Lenin condenó de modo resoluto estos intentos tal y como se constata en su correspondencia con Máximo Gorki y en "Materialismo y Empiriocriticismo”. Y Lifschitz percibió con claridad que Fischer y Garaudy al reivindicar al mito como corazón del arte despojan al marxismo de sus tesis básicas, en una operación de liquidacionismo teórico. Aunque, se podría argumentar que Lifschitz estaba irremediablemente anclado en la fidelidad a principios que ya no tenían fundamento en el mundo contemporáneo o lo que es más, si seguimos a Sartre, es posible afirmar que esta liquidación era necesaria para reconciliar al marxismo con la libertad individual y la democracia.

La polémica de Mijaíl Lifschitz contra el modernismo en los años 60 y 70 está atravesada por la necesidad de concebir la teoría en unidad con la práctica, del análisis concreto de todo fenómeno de la naturaleza, sociedad o pensamiento. No solo en sus enunciados, sino en su lógica en la historia real.

No se debe dar excesivo valor a la lucha de ideas, pero solo mientras ante nosotros jueguen a la guerra con jactancia los sabios de diván. Cuando esas ideas conquistan a las masas, ellas vienen a ser fuerzas materiales y si estas ideas son falsas, entonces ellas devienen en fuerza destructiva y terrible (LIFSCHITZ, 2018b, p. 177).

¿Es posible apelar a la creación de mitos en pos de alcanzar los más nobles ideales? Lifschitz es categórico en su respuesta, las intenciones subjetivas poco importan, la lógica de las cosas actúa por sí misma:

Cuando la filosofía hace de la ceguera su principio, y no de la visión, cuando ella se alía con las sombrías fuerzas de la noche, nada tiene que acusar al mundo. Aceptasteis las condiciones del trabajo, la solución ya no depende de vosotros (LIFSCHITZ, 2018c, p. 145).

En el camino señalado por Fischer y Garaudy la forma desplaza al contenido, se cierra los ojos al mundo real para hundirnos en la subjetividad de lo indecible, la historia se tergiversa de modo consciente ya que la libertad se cifra no en conocer, sino en "crear" y la "creación" es el acto divino de la resurrección de Cristo. En resumen, "el rechazo de la imagen real... el embuste y la validación de la ficción intencionada, el entusiasmo estimulante, esto es, la superchería consciente, la creación de mitos” (2018c, p. 151).

Quien persigue la creación de mitos busca "el aplastamiento de la consciencia consciente" y fugar a la superstición en un afán constante “de romper el espejo de la vida o, por lo menos, de volverlo turbio, opaco" (2018c, p. 151), no importa si esto se hace en nombre del auténtico marxismo o de las ideas progresistas de Occidente, el resultado será siempre el mismo, las ideas más reaccionarias poblarán la consciencia:

... y la pluralidad de intelectos, y el 'historicismo' demoníaco que se convierte en negación plena de la verdad objetiva, y la ineluctabilidad de la destrucción como principio creativo, y la mixtura de ideas místico reaccionarias con el espíritu innovador ultraizquierdista, y la supremacía de la insolente irracionalidad sobre el cadáver de lo lógico, y el regreso no a lo bello, sino a lo más burdamente primitivo como si fuese alta cultura, y también la igualdad de enfermedad y salud con cierta supremacía de lo primero (2018b, p. 175). 
La negación de la verdad objetiva, de la teoría del reflejo y de la dialéctica de la naturaleza en provecho de una praxis que no es la actividad real, la acción crudamente material de la humanidad, sino un demiurgo que engendra la realidad, la subordina para convertirla en una "función de la actividad del hombre" no es ni la liberación ni el camino a la liberación, más bien todo lo contrario:

Es la venganza del siervo, su liberación imaginaria del yugo de la necesidad, una salida fácil. ¡Y si solo fuese una salida! Existe una trabazón fatal entre la forma de protesta servil y la propia opresión (LIFSCHITZ, 2018c, p. 152).

Marxistas del tipo Fischer y Garaudy nos piden repudiar el pensamiento racional y los sentimientos diáfanos en provecho de una nueva superstición que se impone no a través de la comprensión, sino mediante la hipnosis de masas. En opinión de Lifschitz, teorías semejantes anhelan la multitud dirigida mediante la sugestión "capaz de correr tras la carroza del Cesar", no al pueblo que se conforma de personalidades conscientes, no a la actividad autónoma de las masas, sino "la sustitución de la verdad objetiva y su imagen real por la hipnótica voluntad artística capaz de torcer la consciencia de la gente en todos los lados y en obligar al espectador a engullir todo lo que convenga" (LIFSCHITZ, 2018d, p. 95). Un urinario es seleccionado por alguien y colocado en un museo, se nos dice que esto no solo es arte, sino la expresión suprema de la creatividad humana, ¿por qué se atribuye al supuesto artista tan alto grado de genialidad? ¿por qué no a los obreros que fabricaron el urinario? Por un sencilla razón, lo que importa aquí es la apoteosis de la "personalidad creativa" y no el resultado, la obra es en todo caso innecesaria (LIFSCHITZ, 2018e, pp. 127-129). Aquí la apoteosis de la personalidad "creadora" se entrelaza con la negación del contenido objetivo de la consciencia que se considera nociva ("ideología" en Fischer) o imposible (Sartre) en virtud de su absoluta condicionalidad dando pie a la división de la humanidad en dos estratos:

Unos son producto ciego de su medio y de la influencia sobre ella de diferentes medios de comunicación, como la literatura, pintura, cinematografía, televisión y otros poderosos instrumentos de control de consciencias ajenas; otros permanecen tras bastidores y controlan a la masa de seres sencillos. Estos tecnócratas, behavioristas, ingenieros en relaciones humanas, sociólogos; para abreviar, sacerdotes egipcios que están a la cabeza de la sociedad (LIFSCHITZ, 2018f, p. 127).

De una parte está el "creador"con el don de imponer a las manchas amorfas como arte sublime y de la otra a la masa simplona que baja la cabeza y se somete a los designios de esta casta intelectual. En numerosos pasajes de su crítica al modernismo y la sociología vulgar Lifschitz señaló que oculto tras la vocinglería ultraizquierdista se encuentra un viejo prejuicio secular inherente al dominio de clases que revela la estrecha relación entre la separación del trabajo manual e intelectual y el surgimiento de la propiedad privada y el Estado. Engels en un pasaje de "El papel del trabajo en la transformación del mono en hombre" señala:

Se desarrollaron el derecho y la política y, con ellos, el reflejo fantástico de las cosas humanas en la cabeza del hombre: la religión. Ante estas creaciones, que empezaron presentándose como productos de la cabeza y que parecían dominar las sociedades humanas, fueron pasando a segundo plano los productos más modestos de la mano trabajadora, tanto más cuanto que la cabeza encargada de planear el trabajo pudo, ya en una fase muy temprana de desarrollo de la sociedad (por ejemplo, ya en el seno de la simple familia), hacer que el trabajo planeado fuese 
ejecutado por otras manos que las suyas. Todos los méritos del rápido progreso de la civilización se atribuyeron a la cabeza, al desarrollo y a la actividad del cerebro... (ENGELS, 1961, p. 145)

Quienes ven al trabajo intelectual como el único verdaderamente creativo al punto de considerar que la materia es un obstáculo a ser eliminado en el camino para la plena expresión de la personalidad creadora solo desnudan hasta qué punto sus consciencias están atrapadas por las ideas más odiosas de las clases dominantes. El sacerdote católico pronuncia unas palabras mágicas y convierte el simple H20 en agua bendita, sustancia con poderes sobrenaturales, de igual manera el artista modernista prepara un discurso enrevesado que le otorga el poder superhumano de metamorfosear una banana pegada con cinta adhesiva en la pared en poderosa expresión del espíritu humano. Paradójicamente, en tanto más ruidosa sea la proclama del artista de su total libertad con respecto a la realidad exterior más se encuentra sometido a la más grosera cosificación.

La postergación del tema, el desalojo del contenido que tanto fascinaron a Ernst Fischer como un apartamiento de la ideología y a Garaudy como la liberación de la creación pura se liga con el dominio del trabajo abstracto sobre el trabajo concreto, de lo muerto sobre lo vivo que se da en la vida económica de la obra de arte modernista "completamente ficticia desde el punto de vista de su base cualitativa, natural" (LIFSCHITZ, 2018d, p. 75).

Cuando el capital somete la creación espiritual a las leyes de la producción material, toda la perversidad de este régimen social, la hipertrofia de las formas sociales que le es inherente, el aislamiento del contenido real, se manifiesta en la febril convencionalidad que alcanza dimensiones gigantes. La obra del artista, que en su lado convencional posterga más y más el valor de la representación de la vida, es el objeto ideal para la especulación. El capital entra en esta esfera sirviéndose de las manchas de tinta de Pollock o de los recibos que Klein daba a sus compradores en lugar de un cuadro, como simples signos del valor, indiferentes en esencia con el mérito estético de la pintura. Ello no incomoda al contenido real de la mercancía (2018d, p. 75).

La más brutal mistificación capitalista es la forma vacía de contenido capaz de fructificar su valor con independencia de la reproducción, la producción material es negada, el capital aparece como sustancia que se valoriza a sí misma como interés, dividendos y especulaciones. Una obra de arte se valúa y se comercia en función de su cotización monetaria presente y futura hasta que finalmente el único valor de la obra es su valor, porque carece de todo contenido estético.

\section{Breves conclusiones}

Sartre negó la dialéctica de la naturaleza apoyándose en una concepción empirista del conocimiento en las ciencias naturales, ya Engels advirtió que esta posición conduce al peor tipo de superstición y aunque Sartre no era un devoto espiritista, sus criterios nos llevan en última instancia a otro tipo de mixtificaciones.

En tanto y cuanto para Sartre solo existe lo individual, la dialéctica se reduce a la acción libre del individuo contrarrestada por la necesidad entendida como el conjunto de acciones de los otros, por ende, mi libertad termina donde empieza la de los demás5. Para Sartre lo infinito, si existe, es la sucesión de las cosas 
finitas que están unas junto a las otras en un espíritu que recuerda a William de Ockham, por lo que en él está ausente toda verdadera dialéctica y le es incomprensible la tesis de Engels: el conocimiento de la infinitud se da en y a través de la finitud.

Los postulados de Sartre contienen una noción de libertad que requiere la anulación total de la necesidad. De allí su rechazo al reflejo, pues a su entender si el conocimiento es reflejo del mundo esté es condicionado y por lo tanto no es libre, concepción que encuentra su máxima expresión en las ideas estéticas de Ernst Fischer, Roger Garaudy y del propio Sartre que se reducen a la idea introspeccionista de Wundt: el conocimiento auténtico de la personalidad humana está en la contemplación del Yo depurado de toda carnalidad sensible. Posición que poco se diferencia de la religiosidad y su búsqueda de las verdades más altas en lo profundo del alma.

La contraposición abstracta de imitación y creación desemboca en el reemplazo del reflejo por el mito que se introduce como fuente nueva y superior de verdad. No el mundo sensible, sino el mundo interno, indecible e inexpresable, esto es, se llega al rechazo de la tesis básica del marxismo, el ser social determina la consciencia. Irónicamente tales construcciones teóricas terminan en la apología de la falsedad, la superstición consciente y el ritual hipnótico cuyos modelos reales son la violencia y demagogia de las clases propietarias. El arte vaciado de contenido se reduce a la apoteosis de la personalidad del artista que encerrada en sí misma deriva en la pose y la gestualidad propias a todos los sumos sacerdotes desde los tiempos de Chavín de Huántar y cuyo único contenido es la exaltación de los rasgos parasitarios de las clases dominantes y que existe sometida al fetichismo de la forma valor llevado a su extremo.

Pese a todas las ilusiones e incluso a despecho de las buenas intenciones de quienes buscaron la libertad en una praxis libre de su materialidad, en un conocimiento ajeno a todo reflejo y en una creación ajena a toda necesidad el resultado es la capitulación ante las ideas que consagran la esclavitud secular de clase. El reflejo más o menos profundo de la realidad es producto del trabajo arduo de las manos y la cabeza, una labor difícil que choca con la resistencia obstinada de la materia que a despecho de todos nuestros deseos persiste en su propias leyes y que solo se somete cuando nos sometemos a ella.

Hegel ha sido el primero en exponer rectamente la relación entre libertad y necesidad. Para él, la libertad es la comprensión de la necesidad. "La necesidad es ciega sólo en la medida en que no está sometida al concepto." La libertad no consiste en una soñada independencia respecto de las leyes naturales, sino en el reconocimiento de esas leyes y en la posibilidad, así dada, de hacerlas obrar según un plan para determinados fines. Esto vale tanto respecto de las leyes de la naturaleza externa cuanto respecto de aquellas que regulan el ser somático y espiritual del hombre mismo: dos clases de leyes que podemos separar a lo sumo en la representación, no en la realidad. La libertad de la voluntad no significa, pues, más que la capacidad de poder decidir con conocimiento de causa. Cuanto más libre es el juicio de un ser humano respecto de un determinado punto problemático, con tanta mayor necesidad estará determinado el contenido de ese juicio; mientras que la inseguridad debida a la ignorancia y que elige con aparente arbitrio entre posibilidades de decisión diversas y contradictorias prueba con ello su propia ilibertad, su situación de dominada por el objeto al que precisamente tendría que dominar. La libertad consiste, pues, en el dominio sobre nosotros mismos y sobre la naturaleza exterior, basado en el conocimiento de las necesidades naturales; por eso es necesariamente un producto de la evolución histórica (ENGELS, 1968, p. 104).

Las obras de los años 60 y 70 de Mijaíl Lifschitz tuvieron la virtud de evidenciar ese vínculo no siempre comprendido entre la concepción marxista de libertad y necesidad que se encuentra implícita en la 
obra de Marx y expuesta por Engels en sus trabajos filosóficos más conocidos, que es el verdadero fundamento de toda concepción democrática que apela a las masas y se encuentran inserta en las ideas y práctica de Lenin.

\begin{abstract}
Que nuestra bandera sea la doctrina de Lenin. Esta es la doctrina sobre la iniciativa propia de las masas populares y todo cesarismo junto con esa atmósfera que le es inherente de milagros y supersticiones, es hostil a nuestras ideas. Estamos por la combinación del entusiasmo popular vivo con la clara luz de la ciencia y la comprensión de la genuina realidad, accesible a todo hombre que sepa leer y escribir, con todos los elementos de la cultura artística desarrollada, obtenida por la gente que como personalidad acaba de salir de la obediencia ciega a las formas heredadas de vida (LIFSCHITZ, 2018c, pp. 155-156).
\end{abstract}

\title{
Bibliografia:
}

ENGELS, Federico. Dialéctica de la naturaleza. 1" ed. CDMX: Grijalbo, 1961.

ENGELS, Federico. Anti-Dühring. La subversión de la ciencia por el señor Eugen Dühring. CDMX: Grijalbo, 1968.

FISCHER, Ernst. Arte y coexistencia. 1ra. ed. Barcelona: Ediciones Península, 1968.

GARAUDY, Roger. D’un réalisme sans rivages. París: PLON, 1963.

GARAUDY, Roger. ¿Se puede ser comunista hoy? 1 ra. ed. CDMX: Grijalbo, 1970.

HEGEL, G. W. F. Ciencia de la Lógica. 4. ed. Buenos Aires: Ediciones Solar, 1976.

KOHAN, Néstor. Marx en su (Tercer) Mundo. 2" ed. La Habana: Centro de Investigación y Desarrollo de la Cultura Cubana Juan Marinello, 2003.

LIFSCHITZ, Mij. En defensa de la tribu de los insolentes. En: El arte y la ideología. Quito: EDITHOR, 2018. a. p. 186-212.

LIFSCHITZ, Mij. ¡Cuidado con la humanidad! En: El arte y la ideología. Quito: EDITHOR, 2018. b. p. 159-185.

LIFSCHITZ, Mij. ¿Por qué no soy un modernista? En: El arte y la ideología. 1ra. ed. Quito: EDITHOR, 2018. c. p. 139-156.

LIFSCHITZ, Mij. Fenomenología de la lata de conserva. En: El arte y la ideología. 1ra. ed. Quito: EDITHOR, 2018. d. p. 62-99.

LIFSCHITZ, Mij. El modernismo como fenómeno de la ideología burguesa contemporánea. En: El arte y la ideología. Quito: EDITHOR, 2018. e. p. 112-138.

LIFSCHITZ, Mij. Sociología vulgar. En: Libertad de la personalidad. 2da. ed. Quito: EDITHOR, 2018. f. p. $101-128$.

LIFSCHITZ, Mij.; LUKÁCS, Georg. Sobre la situación del marxismo y la lucha de ideas. En: El arte y la ideología. Quito: EDITHOR, 2018. p. 213-218.

PETROVIC, Gajo. El materialismo histórico, la filosofía de la praxis y el pensamiento de la revolución.

En: Praxis y filosofía. Ensayos en homenaje a Adolfo Sanchez Vazquez. CDMX: Grijalbo, 1985. p. $39-56$.

PIEDRA ARENCIBIA, Rogney. Marxismo y dialéctica de la naturaleza. 2da. ed. Quito: EDITHOR, 2019.

SARTRE, Jean-Paul. Crítica de la Razón Dialéctica. Tomo I. Buenos Aires: Editorial Losada, 1963.

SARTRE, Jean-Paul; GARAUDY, Roger; FISCHER, Ernst; HAJEK, Jiri; HOFFMEISTER, Adolph; KUNDERA, Milan; PUJMAN, Petr. Entretien à Prague sur la notion de «décadence». La Nouvelle

Critique, [S. l.], n. 156-157, p. 71-84, 1964. 


\section{Notas}

1 Psicólogo industrial formado pela Universidade Central de Quito (Equador). Traduziu para o espanhol vários livros de filósofos como Evald Iliénkov, Mikhail Lifschitz e Valeri Bosenko. Orcid: http://orcid.org/0000-0002-8678-0233 Email: psicvictorcarrion@gmail.com

2 El lector puede encontrar un análisis minucioso de la argumentación filosófica antiengelsiana en el libro de Rogney Piedra Arencibia "Marxismo y dialéctica de la naturaleza" (EDITHOR, 2019).

${ }^{3}$ Néstor Kohan toma la acusación contra Engels y la erige en fundamento de una concepción general de la historia del marxismo. El materialismo de Engels, que supuestamente es muy distinto al materialismo de Marx, "terminó naturalizando la historia" y subordinando el sujeto al objeto "como una construcción ontológica de la cual se derivan, en segundo momento, consecuencias gnoseológicas", perdiéndose así "la unidad sujeto-objeto". Engels sentó, supuestamente, el núcleo de pensamiento seguido por Karl Kautsky y Gueorgui Plejánov, "un determinismo histórico lindante con el fatalismo" que "hará escuela en los principales exponentes de la recepción dogmática y eurocentrista del marxismo latinoamericano" (KOHAN, 2003, pp. 33, 38-39).

4 "El quid del problema radica en que, Schmidt, acepta sin crítica las representaciones propias del positivismo sobre el método y el objeto de las ciencias naturales. Asimismo, sucede con Lucio Colletti para quien la ciencia siempre ha sido y será metafísica en el sentido positivista. En esto consiste la inconfesa idolatría a las ciencias naturales por parte de estos marxistas, manifiesta en su virtual abandono de la reflexión filosófica sobre esta importante área. Y, una vez más, encontramos otra inconsecuencia común en los críticos de Engels. Es típico de los existencialistas (Sartre, Abbagnano, etc.) acusar a la dialéctica engelsiana de la naturaleza de positivista; pero en realidad - y esto es muy irónico -, en la práctica teórica, son ellos y no Engels los que terminan en la postura positivista respecto al tema que nos incumbe" (PIEDRA ARENCIBIA, 2019, pp. 183-184).

5 Ver SARTRE, 1963, pp. 393-402. 